\title{
Modelling association between two Multiple Response Categorical Variables (MRCV) using generalized log-linear models: the case of urban agriculture in Mutare City
}

Absai Chakaipa ${ }^{1}$, Vitalis Basera ${ }^{2}$, Phamella Dube ${ }^{3}$

Manicaland State University of Applied Sciences, Mutare, Zimbabwe $e^{1,2,3}$

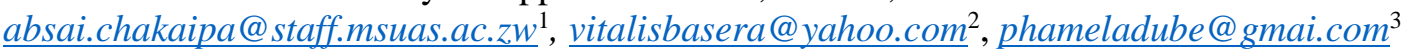

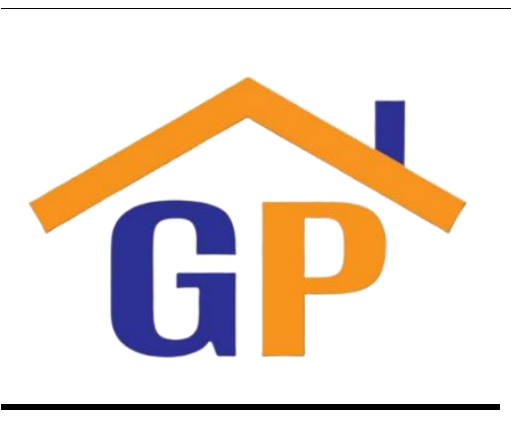

Article History

Received on 27 January 2021

Revised on 28 January 2021

Accepted on 16 February 2021

\begin{abstract}
Purpose: This research aimed to apply log-linear modelling to model association between multiple response categorical variables (MRCV) on urban agriculture and enhance data analysis of the paper by Basera, Chakaipa, \& Dube (2020) impetus of urban agriculture on open spaces of Mutare City.
\end{abstract}

Research methodology: The research data was obtained from households and farmers in Mutare City - urban and peri-urban (inclusive of plots in Weirmouth Park and Fern Valley area in December 2020. A total of one hundred and fifteen (115) household farmers were surveyed.

Results: Simultaneous Pairwise Marginal Independence (SPMI) tests revealed the presence of associations. Log-linear tests revealed a perfect fit based on small standardized Pearson residuals and a strong positive association based on observed and model-predicted odds ratios on-field agricultural activities and use of herbicides. Log-linear and further application of heterogeneity tests revealed partial and near no perfect fit in other pairs of MRCVs with a strong negative association between municipality vacant places and field agricultural activities.

Limitations: The research could not carry out log-linear model associations of three or more MRCVs because files exceeded 2GB in memory on both MI.test () function for SPMI tests and genloglin regressions.

Contribution: The study contributes to urban agriculture planning especially in enactment of urban agriculture laws, agriculture one stop shop business centers housing farm input supply shops, farm produce shops, and determining fit support that can be rendered to urban farmers.

Keywords: Multiple Response Categorical Variables (MRCV), Association, Urban agriculture

How to cite: Chakaipa, A., Basera, V., \& Dube, P. (2021). Modelling Association between two Multiple Response Categorical Variables (MRCV) using generalized log-linear models: the case of urban agriculture in Mutare City. Journal of Social, Humanity, and Education, 1(2), 117-132.

\section{Introduction}

According to Basera, Chakaipa and Dube (2020), urban agricultural activities need a support system in terms of farming inputs and pesticides and training to be in place for it to sustain livelihoods at the family level, community level, and as create employment opportunities through sales at the local market. In Mutare, the local authority does not support urban agriculture as they are not supporting the 
farming activities by enacting enabling bylaws and organising farmers. The shortage of food and income in urban households is one of the main drivers of urban farming as the families try to be food secure by embarking on farming. Unemployment is ever increasing in the country and if urban agriculture is embraced, it can create employment for the population. There is a need to support urban agriculture with inputs and training on sustainable agricultural methods compatible with urban settings. Practicing urban agriculture in cooperatives or groups can lead to economies of scale and better chances to secure support and lobby authorities for support. Non-governmental organizations like Zimbabwe Poultry Association can help urban farmers in livestock farming strengthen the agriculture value chain through market linkages and service linkages for economies of scale and bargaining power. There is a need to involve external stakeholders in coordinating urban horticulture and provision of Information and Communication Technologies (ICT) solutions and developing digital platforms to strengthen performance at every level. There is a need to extend government agriculture support schemes like Presidential inputs, Agriculture mechanization to the urban population since it can add to national food security. The findings on urban agriculture's impetus are limited by the small sample size (76 households) and lack of multiple response questions relationship analysis. The research only utilised single response categorical variables (SRCV) and one multiple response categorical variable (MRCV) which does not capture association structures.

The sample size was increased to 115 . The survey included farmers in peri urban plots (Weirmouth and Fern Valley). Such farmers are into multi agriculture activities, including fruit, piggery, and poultry production. Multiple research questions were used: Use of organic fertilisers, chemical (phosphatic) fertilizers or both in agriculture activities, Sources of information for agriculture farming such as specialized consultant, veterinarians, ministry of agriculture extension service workers, magazines, input or feed supply companies agents. The Multiple Response categorical variable (MRCV) in depth analysis was used to capture association structure and correlate subject for independence between two or more multiple responses categorical variables.

\section{Literature review}

\subsection{Urban agriculture}

Mutare city is one of the oldest cities in Zimbabwe in the eastern part of the country linking Zimbabwe to Mozambique and is the gateway to the sea. The city sits on 16500 hectares of land with an estimated population of 188243 people, 4662 low-density housing units, 926 medium density housing units and 43620 high-density housing units (City of Mutare, 2020). The advent of economic crisis (unemployment, inflation), political crisis, natural disasters, pandemics of diseases -lockdown measures to curb the spread of COVID-19 saw a massive increase in the city's urban agriculture activities.

Urban agriculture definition, factors, impact and challenges are summarised according to literature as shown in Table 1.

Table 1: Urban agriculture summary

\begin{tabular}{|l|l|}
\hline Author & Definition of Urban Agriculture \\
\hline$\underline{\text { FAO (2007) }}$ & $\begin{array}{l}\text { The growing of plants and the raising of animals for food and other uses within } \\
\text { and around cities and towns, and related activities such as the production and } \\
\text { delivery of inputs, processing and marketing of products }\end{array}$ \\
\hline$\underline{\text { Mouget (2000) }}$ & $\begin{array}{l}\text { Is located within (intra-urban) or on the fringe (peri-urban) of a town, a city or a } \\
\text { metropolis, and grows or raises, processes and distributes a diversity of food and } \\
\text { non-food products }\end{array}$ \\
\hline Authors & Factors affecting agriculture \\
\hline $\begin{array}{l}\text { Mkhokheli (2012), } \\
\text { Chaminuka \& Dube } \\
\frac{\text { \& Mashapa (2016), }}{\text { Nwosisi \& Nandwani }} \\
\underline{\text { (2018), }}\end{array}$ & $\begin{array}{l}\text { Severe food crisis, failure of land reform program, worsening poverty, agriculture } \\
\text { market failure, political and economic challenges due to failure of government } \\
\text { economic policies }\end{array}$ \\
\hline$\underline{\text { Gondo, et al., (2017) }}$ & Increasing poverty, hunger and unemployment \\
\hline
\end{tabular}




\begin{tabular}{|c|c|}
\hline $\begin{array}{l}\text { Danso, Hope, \& Drechsel } \\
\text { (2014), FAO (2007) }\end{array}$ & $\begin{array}{l}\text { Increasing demand for food, closeness to marketplaces and obtainability of cheap } \\
\text { resources }\end{array}$ \\
\hline Kennard \& Bamford & Need for fresh food, reduced transport, storage costs and reduced the value chain \\
\hline Author & Impact of urban agriculture \\
\hline $\begin{array}{lll}\text { RUAF } & (2020), & \text { FAO } \\
(2020) & \end{array}$ & Support food security and livelihoods. \\
\hline Amao $(2020)$ & Add to balanced diet of the urbanites \\
\hline $\begin{array}{l}\text { Gandawa (2020), World } \\
\text { Bank, (200) }\end{array}$ & Creates employment and increase incomes \\
\hline $\begin{array}{l}\text { Edmondson, et al., (2020), } \\
\text { Martin-Moreau } \\
\text { Ménascé (2019) }\end{array}$ & $\begin{array}{l}\text { Reduce poverty, environmental management and economic growth in developing } \\
\text { countries. Helps in city buffer zone management, supporting climate change } \\
\text { adaptation plans, land - reclamation and protection, waste management, urban } \\
\text { greening, and biodiversity management. }\end{array}$ \\
\hline FAO (2015) & Give rise to urban greening, open space greening, reduction of noise and pollution. \\
\hline $\begin{array}{l}\text { Poverty Reduction Trust } \\
(2019)\end{array}$ & Health hazard and siltation \\
\hline Author & Challenges of urban agriculture \\
\hline Ziwenga (2014) & Lack of basic amenities to manage water and waste \\
\hline $\begin{array}{l}\text { Eigenbrod \& Gruda } \\
(2015)\end{array}$ & Higher land prices and urban pollution \\
\hline $\begin{array}{l}\text { Chaminuka \& Dube } \\
\text { (2017), Kawadza (2019) }\end{array}$ & $\begin{array}{l}\text { Urban farmers face challenges from thieves, animals destroying their crops and } \\
\text { lack of funding. }\end{array}$ \\
\hline
\end{tabular}

2.1.1. Multiple Response Categorical Variables (MRCV) "Pick any or Choose all that apply variables" Surveys are usually characterized by questions requiring respondents to choose more than one response from a set of items. Bilder and Loughin, (2007) classify such questions into multiple response categorical variables (MRCVs). MRCVs arise in surveys from a variety of settings, including swine management (Agresti \& Liu, 1999; Bilder \& Loughin, 2004), contraceptive use (Bilder \& Loughin, 2001) and understanding patient symptoms (Bilder \& Loughin, 2001). More generally, these variables arise from any multivariate binary response measurement. Responses to a MRCV can be all negative, one positive, any combination of positives, or all positive responses. Although several studies have recognized the existence of multiple response variables, they neglect the implication of analyzing those variables. Some researchers, deliberately ignored the appropriate analysis of multiple response categorial variables and resort to Chi-test as a method of analysis as perceived by Lavassani, Movahedi and Kumar (2009). An example is Tudor, Micua and Condeia (2014), who used the Chi-test to analyze the association between agriculture practices considered necessary by agriculture producers in the Arges County. The researcher ignores the estimation of the impact of those agriculture practices to production, growth and yield return to the farmers. Lavassani, Movahedi and Kumar (2009), also cited other scholars like Stallings and Ferris (1988) who after recognizing the existence of multiple response variables, proceed to use the classical (Pearson) chi-square as an analytical tool which was an inappropriate analytical for complex data. Decay \& Thomas (2000) condemns the Pearson Chi-test citing that contingency tables' outcomes are exaggerated. Secondly, he criticizes the analytical tool for violating the assumption of independence, and the statistic fails to exhibit a large-sample chi-squared distribution.

The complexity of multiple categorical data responses dates back to the 1970s. Hence statisticians have strategized models to deal with complex data. Some cited examples in this paper is the pseudo-chisquared test recommended by Umesh (1995). Loughin and Scherer, (1998) developed a bootstrap test for investigating relationships between one categorical variable to multiple-category responses from individual respondents in two-way tables. However, the technicality with this procedure was computationally involved and uncommon to many practitioners. These drawbacks prompted other statisticians like Decay and Thomas (2000) to develop a corrected chi-square statistic to analyze 
complex survey data from Rao and Scott (1981)'s methods. The first order Rao-Scott chi-square was successfully employed by (Lavassani, Movahedi and Kumar ,2009) in establishing the association of four elements considered in the implementation of Enterprise Systems. A follow up from Thomas and Decady (2000) suggests non-model-based approaches in using extensions of Pearson chi-square tests. Bilder \& Loughin (2004) came up with the marginal independence test for two multiple-response categorical variables.

Agresti and Liu (1999, 2001), and Coull and Agresti (2000) discovered that the generalized log-linear models provided satisfactory results in estimating maximum likelihood ratio and a correct size test for simultaneous pairwise marginal independence (SMPI)than the multivariate binomial logit-normal model. Also, the results from Bonferroni adjustment procedure were consistent when used in the absence of individual subjects. Of all the tests and models discussed previously, the MRCV by Koziol and Bilder (2014) package is deemed most appropriate in estimating the association between two MRCV. The package consists of Pearson chi-square tests for independence and log-linear models, with reliable bootstrap methods and Rao-Scott adjustments for valid inferences.

\subsubsection{Application of multiple response categorical variables methods}

These model of analyzing multiple response categorical variables have been applied to numerous studies. Zhu et al (2006), compared results using structural equation model and a log-linear model in the same data set in examining determining factors of care-givers health derived from two approaches. The data was collected from a cross-section of families in Ontario, Canada of based sample of 468 who had a child with cerebral palsy. The results indicated that they were differences in the two analyses. The Structural Equation Modeling (SEM) results were confirmed by the Log-linear Modeling (LLM) which provided some assurance that the SEM had been sufficiently specified, and that it generally fitted the data. Similarly, Hooker, (2013) analyzed whether there was association between firms in California that create green products and three employment outcomes - net job gain, net job loss, and no net change. The analysis used an ordered logit regression model to predict relationships between private sector firms and the four variables namely age of firm, type of firm, size of the firm, and industry sector. A sample of 622,466 private sector firms were included in the data and the predicted the likelihood of each of the employment outcomes from January 2008 through January 2010 was done. The results showed that the firm's size and industry sector were the strongest predictors of net job gains during the study period, but there was no noticeable difference in the chance that a green or non-green firm would experience a net job gain. Alalaya (2011) investigated the effects of some factors that affect heart diseases such as hypertension, fatty diet, diabetes, smoking, gender, overweight and family history of heart disease in Jordanian hospitals' data. The data was collected through the medical record sheets of patients from three regions of Jordan - north, south and middle area. Log-linear models were used to analyze the data odds ratios, likelihood ratio tests and chi-square, K-terms tests of multiple models in log-linear models, FT-SR to check whether chi-square value were considered the normal distributed (Friedman-Tukey standard residual) were estimated. The results indicate that all variables analyzed together or as groups significantly fit the model. The logistic regression, the R2 was 0,57083 , which stated that the model provides well due to the significance. This shows that heart diseases are the major killer in Jordan. Lorenzoni, et al., (2019) compared the performance of eight Machine Learning Techniques (MLTs) using data from the Gestione Integrata dello Scompenso Cardiaco (GISC) study in the prediction of hospitalization among patients with heart failure. Logistic regression, classification and regression tree, generalized linear model net (GLMN), random forest, logit boost, ad boost, support vector machine, and neural networks were used to assess the practicability of such techniques in predicting hospitalization of 380 patients enrolled in the GISC study. The MLTs were compared both with and without missing data imputation. General, models trained without missing data imputation showed higher predictive performances. The GLMN showed improved performance in predicting hospitalization than the other MLTs, with an average accuracy of $81.2 \%$, positive predictive value $87.5 \%$ and negative predictive value of $75 \%$.

From the literature review, we deduce that multiple response categorical variable models are essential in predicting determinants and establishing correlations for a research outcome. However, the applicability of these models is determined by the type of variables used, the logistic regression model is most suitable if one wants to define the dependent variables and make predictions explicitly. It is also 
easier to include more variables as well as continuous variables. If variables, prognoses and outcomes are categorical, a log-linear analysis is the best tool to use. The approach designed by Koziol and Bilder (2014) best suits analysis of associations between two MRCV and other methods are appropriate for single response categorical variables.

\subsection{Conceptual framework}

According to Basera, (2021) a conceptual framework shows how variables in the research relate to each other to understand a phenomena(on) under study fully. To give a reliable and valid basis of the academic research on modelling association between two multiple response categorical variables (MRCV) using log-linear models in the impetus of urban agriculture in Mutare city a conceptual framework is highlighted. The conceptual framework in Figure 1 links/connect key variables in urban agriculture as guided by how the research questions are answered.

Figure 1: Conceptual framework

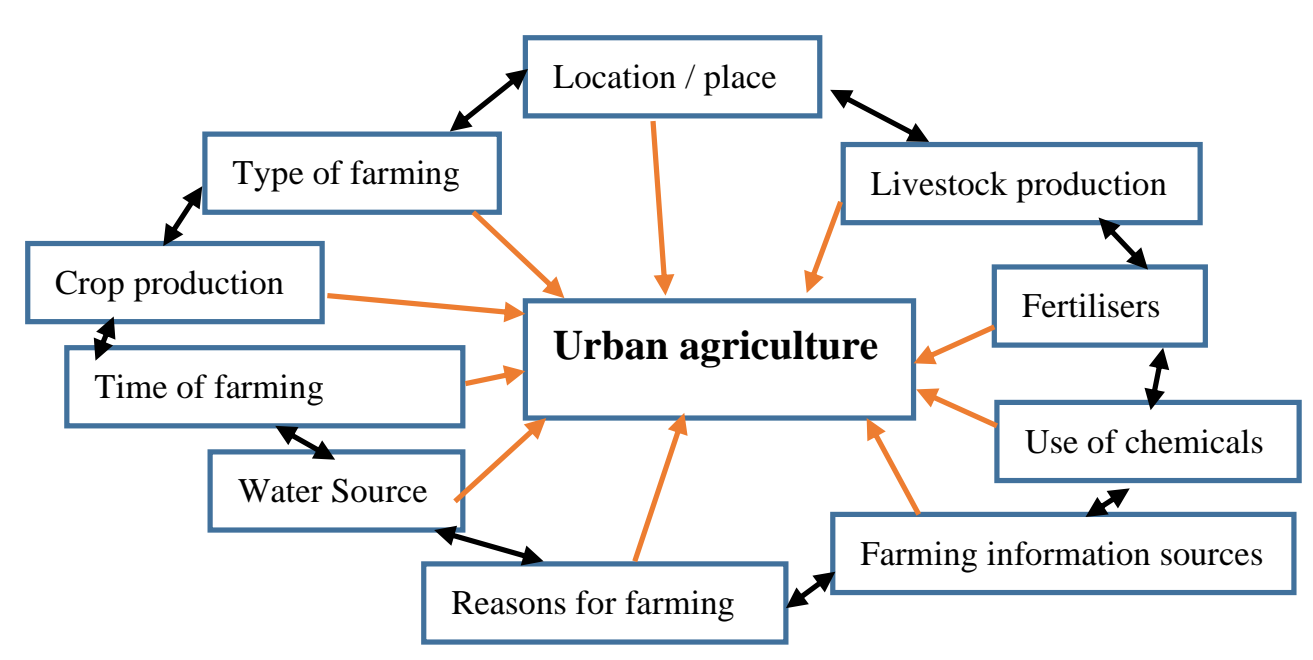

\section{Research methodology}

The research data was obtained from households and farmers in Mutare City - urban and peri-urban (inclusive of plots in Weirmouth Park and Fern Valley area in December 2020. A total of one hundred and fifteen (115) household farmers were surveyed. A total of ten Multiple response questions were used in the survey in total: Questions such as Sources of information for agricultural activities (state extension workers, online sources, farmers associations, friends-relatives, radio-television, feedcompanies), use of fertilizers (organic or non-organic fertilizers), use of chemicals (herbicides or pesticides and animal husbandry activities (poultry, piggery, goats and cattle). The tens precise questions are given as:

Q1. Where do you do your agricultural activities?
a) In your yard
b) Municipality vacant places

Q2. Which urban farming activities do you practice?
a) Beds-vegetables
b) Beds-herbs
c) Beds-fruits
d) Sweet potatoes
e) Mushroom
f) Nursery for seedlings
g) Flowers
h) Groundnuts
i) Grains (e.g. maize)
j) Livestock

c) Rented premises

d) Plot

Q3. If you do animal husbandry/livestock production, what type of live stock do you farm?
a) Poultry
b) Piggery 

c) Goats
d) Cattle

Q4. During which time of the year do you do your agricultural activities?
a) Summer
c) Winter
b) Autumn
d) Spring -

Q5. Do you do dry cultivation or irrigation?
a) Dry cultivation
b) Irrigation

Q6. If do irrigation. What is your source of water?
a) Borehole
c) Pool
b) Tap
d) Pipe/council

Q7. For what purpose do you do urban farming?

a) To augment family income

b) For sale

c) To utilize the available support system

d) As a hobby

Q8. What are your sources of farming information?
a) State extension workers
e) Online sources
b) Magazines
c) Feed/input suppliers
d) Television radio
f) Private consultancy
g) Friends relatives
h) Farmers association

Q9. What type of fertilisers do you use?

a) Organic fertilisers e.g manure, compost

b) Non-organic fertilisers e.g phosphatic, compound, ammonium nitrates

Q10. Do you use chemicals in weed and pest management

a) Herbicides

b) Pesticides

The analysis mostly tested for associations for a pair of MRCVs on the following questions. Research questions of interest where conceptualized as:

A. Is one MRCV response independent of the other MRCV responses?

B. If the two MRCVs are dependent, what is the association structure (is it strong or weak, is it positive or negative?

Modelling such an association structure helps researchers in understanding better the sources of information for farmers, use of herbicides and use of organic fertilizers in farming (most traditional farming methods rarely use herbicides and organically-made fertilizers from shops) and possibly promote/advice on particular type of changes (where necessary). Analysis was done using R software (version 4.0.1) using MRCV package (version 0.3-3) developed by Koziol and Bilder (2014). Data arising from MRCVs was summarized using item response tables (IRTs) showing both positive and negative responses. Assumption: There were no missing observations made throughout the analysis.

\section{Research methodology}

3.1. Simultaneous Pairwise Marginal Independence (SPMI) tests

Generally, the hypotheses are as follows to test for simultaneous pairwise marginal independence (SPMI) tests;

$H_{0}: \gamma_{i j}=\gamma_{+i} \gamma_{+j}$ for $i=1 ; \ldots ; I$ and $j=1 ; \ldots ; J$ the two multiple response questions are independent. $\mathrm{H}_{1}: \gamma_{i j} \neq \gamma_{+i} \gamma_{+j}$ for a least one $(i ; j)$ pair: the two response questions are not independent (have an association).

The marginal log-linear model for SPMI is $\log \left(\mu_{a b i j}\right)=\gamma_{i j}+\eta_{a i j}^{W}+\eta_{b i j}^{Y}$

for $\mathrm{i}=1, \ldots, \mathrm{I}, \mathrm{j}=1, \ldots . . \mathrm{J}, \mathrm{a}=0,1$ and $\mathrm{b}=0,1$

where $\gamma_{i j}$ controls the sample size $\mathrm{n}$ in each sub-table 
$\eta_{a i j}^{W}$ controls the row marginal counts in each sub-table

$\eta_{b i j}^{Y}$ controls the column marginal counts in each sub-table

When the SPMI model is not appropriate, additional parameters measuring the association between $\mathrm{W}$ and $\mathrm{Y}$ are introduced into the model. These models include:

$$
\begin{aligned}
& \log \left(\mu_{a b i j}\right)=\gamma_{i j}+\eta_{a i j}^{W}+\eta_{b i j}^{Y}+\lambda_{a b} \\
& \log \left(\mu_{a b i j}\right)=\gamma_{i j}+\eta_{a i j}^{W}+\eta_{b i j}^{Y}+\lambda_{a b}+\lambda_{a b}^{Y} \text {------- -----------(3) for } \mathrm{W} \text { homogeneous association }
\end{aligned}
$$

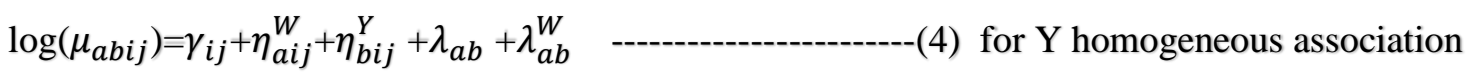

$$
\begin{aligned}
& \log \left(\mu_{a b i j}\right)=\gamma_{i j}+\eta_{a i j}^{W}+\eta_{b i j}^{Y}+\lambda_{a b}+\lambda_{a b}^{Y}+\lambda_{a b}^{W} \text {----------- } \quad \text { (5) for WY-main effects association } \\
& \log \left(\mu_{a b i j}\right)=\gamma_{i j}+\eta_{a i j}^{W}+\eta_{b i j}^{Y}+\lambda_{a b}+\lambda_{a b}^{Y}+\lambda_{a b}^{W}+\lambda_{a b}^{W Y} \text {----------(6) saturated model }
\end{aligned}
$$

The homogenous association allows odds ratios to be equal to 1 in each sub-table and is suitable when associations between $\mathrm{W}$ and $\mathrm{Y}$ are nearly at the same level. The $\mathrm{Y}$ main effects model allows the subtable's odds ratios to vary across $\mathrm{Y}$ items but constant within the $\mathrm{W}$ items. The WY-main effects allows main effects of both $\mathrm{W}$ and $\mathrm{Y}$ odds ratios to vary. The Saturated model puts no constraints on the odds ratios of $\mathrm{W}$ and $\mathrm{Y}$ combination.

The analysis used Ymain effects, W main effects and WY-main effects of association.

The MI. test () function offers three sets of testing methods: a nonparametric bootstrap approach, a RaoScott second-order adjustment, and a Bonferroni adjustment, that can be used in conjunction with the modified statistic to construct an appropriate test for independence.

The analysis was done mostly using R-software (R 4.0.3) and package MRCV (Multiple Response Categorical Variable) analysis. The first part will address whether one MRCV variable is independent of the MRCV responses using the M1.test () function found in the MRCV package of R software. The second part will determine the type of the association structures using standardized residuals, odds ratios (both observed and model predicted), bootstrap and second-order Rao-Scott p-values and Pearson goodness of fit statistics.

\section{Results and discussion}

A total of 115 participated in the survey. The item response table (IRT) results in Table 1 revealed that 46 respondents used herbicides on beds-vegetables, 53 respondents used herbicides on grains.

\begin{tabular}{|c|c|c|c|c|c|c|c|c|c|c|}
\hline & & Beds-veg & Beds-herbs & Beds-fruits & Sweet pot & Mushroom & Nursery seeds & Flowers & Groundnuts & Grains \\
\hline & & 1 & $\begin{array}{ll}\mathbf{0} & 1\end{array}$ & $\begin{array}{ll}\mathbf{0} & 1\end{array}$ & $\begin{array}{ll}\mathbf{0} & 1\end{array}$ & $\begin{array}{ll}\mathbf{0} & \mathbf{1}\end{array}$ & $\begin{array}{ll}\mathbf{0} & 1\end{array}$ & $\begin{array}{ll}\mathbf{0} & 1\end{array}$ & $\begin{array}{ll}\mathbf{0} & 1\end{array}$ & $\begin{array}{ll}\mathbf{0} & 1\end{array}$ \\
\hline \multirow{2}{*}{ 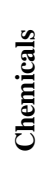 } & $\begin{array}{r}0 \\
\text { Herbicides } 1\end{array}$ & $\begin{array}{rr}11 & 4 \\
54 & 46\end{array}$ & $\begin{array}{ll}57 & 42 \\
8 & 8\end{array}$ & $\begin{array}{ll}49 & 25 \\
16 & 25\end{array}$ & $\begin{array}{ll}49 & 28 \\
16 & 22\end{array}$ & $\begin{array}{ll}60 & 35 \\
5 & 15\end{array}$ & $\begin{array}{ll}56 & 29 \\
9 & 21\end{array}$ & $\begin{array}{ll}60 & 35 \\
5 & 15\end{array}$ & $\begin{array}{lc}58 & 32 \\
7 & 18\end{array}$ & $\begin{array}{ll}20 & 7 \\
45 & 53\end{array}$ \\
\hline & $\begin{array}{ll} & 0 \\
\text { Pesticides } & 1\end{array}$ & $\begin{array}{lr}0 & 15 \\
6 & 94\end{array}$ & $\begin{array}{ll}5 & 94 \\
1 & 15\end{array}$ & $\begin{array}{cc}5 & 69 \\
1 & 40\end{array}$ & $\begin{array}{lc}5 & 72 \\
1 & 37\end{array}$ & $\begin{array}{ll}6 & 89 \\
0 & 20\end{array}$ & $\begin{array}{cc}5 & 80 \\
1 & 29\end{array}$ & $\begin{array}{ll}6 & 89 \\
0 & 20\end{array}$ & $\begin{array}{cc}6 & 84 \\
0 & 25\end{array}$ & $\begin{array}{ll}3 & 24 \\
3 & 85\end{array}$ \\
\hline
\end{tabular}

Table 2: Item response table showing number of positive and negative responses on agriculture activities and use of chemicals.

Section A dealt with SPMI (tests for association) whilst section B dealt with log-linear tests (testing on type of associations and testing on perfect fit tests) 
4.1. Section A: Simultaneous Pairwise Marginal Independence (SPMI) tests (tests for association) 4.1.1. Is there any association between questions place/location vs urban agriculture activities? (Q1 vs Q2)

Testing for marginal independence with Simultaneous pairwise marginal independence (SPMI) tests

Generally, the hypotheses is as follows to test for simultaneous pairwise marginal independence (SPMI) tests

$H_{0}: \gamma_{i j}=\gamma_{+i} \gamma_{+j}$ for $i=1 ; \ldots ; I$ and $j=1 ; \ldots ; J$ the two multiple response questions are independent. $\mathrm{H}_{1}: \gamma_{i j} \neq \gamma_{+i} \gamma_{+j}$ for a least one $(i ; j)$ pair: the two response questions are not independent (have an association).

Table 3: SPMI tests between place/location and agriculture activities

\begin{tabular}{|l|l|l|l|l|l|}
\hline Test type & B resamples & p-value \\
\hline Bootstrap & \multicolumn{2}{l}{2000} & & p-boot $=0.0005$ \\
\hline
\end{tabular}

Result: An MI.test () function results from table 2a reveals that both the Bootstrap tests, the Bonferroni and Second-order Rao-Scott Adjusted results gave p-values of 0.0005, 0.0001 and 0.0001, respectively , which are all significant at 5\% level. This indicates strong evidence against SPMI. The $X S 2, i, j$ and corresponding Bonferroni adjusted p-values indicate a significant association for the $(Q 1 b, Q 2 c),(Q 1 b$, $Q 2 h),(\mathrm{Q} 1 \mathrm{~d}, \mathrm{Q} 2 \mathrm{c})$ and $(Q 1 d, Q 2 h)$ combinations. In this case associations are observed between response of municipality vacant places and beds-fruits (and groundnuts) and plots and beds-fruits (and groundnuts). It means that with the availability of municipality open spaces the practice of agriculture production increases with other cropping activities either increase.

4.1.2. MI.test for association between questions agriculture activities vs use of chemicals

Table 4: MI.test for association between questions agricultural activities vs use of chemicals (herbicides or pesticides)

\begin{tabular}{|c|c|c|c|c|c|c|c|c|c|}
\hline \multicolumn{5}{|c|}{ Test type } & \multicolumn{3}{|c|}{ B resamples } & \multicolumn{2}{|l|}{ p-value } \\
\hline \multicolumn{5}{|c|}{ Bootstrap } & \multicolumn{3}{|l|}{1994} & \multicolumn{2}{|c|}{ p-boot $=0.0005$} \\
\hline \multicolumn{5}{|c|}{ Second-order Rao-Scott adjust } & \multicolumn{3}{|l|}{1994} & \multicolumn{2}{|c|}{ p-adjust $=0.0001$} \\
\hline \multicolumn{5}{|c|}{ Bonferroni adjustment } & \multicolumn{2}{|l|}{1994} & & \multicolumn{2}{|c|}{ p-adjust $=0.0118$} \\
\hline \multicolumn{10}{|c|}{ Bonferroni Adjusted Results (p.adj = 0.0118) } \\
\hline & Q2a & Q2b & Q2c & Q2d & Q2e & Q2f & Q2g & Q2h & Q2i \\
\hline Q10a & 1.00 & 1.00 & 0.0871 & 0.5123 & 0.0316 & 0.0118 & 0.0316 & 0.0206 & 0.6381 \\
\hline Q10b & 1.00 & 1.00 & 1.00 & 1.00 & 1.00 & 1.00 & 1.00 & 1.00 & 1.00 \\
\hline
\end{tabular}

Result: Both the Bootstrap tests, the Bonferroni and Second-order Rao-Scott Adjusted results, gave pvalues of $0.0005,0.0001$ and 0.0118 , respectively, which are all significant at $5 \%$ level. This indicates strong evidence against SPMI. The $X S 2, i, j$ and corresponding Bonferroni adjusted p-values indicate a significant association for the $(Q 2 e, Q 10 a),(Q 2 f, Q 10 a),(\mathrm{Q} 2 \mathrm{~g}, \mathrm{Q} 10 \mathrm{a})$, and $(\mathrm{Q} 2 \mathrm{~h}, \mathrm{Q} 10 \mathrm{a})$ combinations. In 
this case, associations are observed between the response of yard places and poultry activities, plots and (poultry activities, piggery, goats and cattle activities). What it means is that those with big land size, like those in the peri urban plots, do keep livestock, the larger the land size the increase in livestock farming.

4.1.3 MI. test for association between questions animal husbandry activities vs source of information for agricultural activities

Table 5: MI. test for association between questions animal husbandry activities vs source of information for agricultural activities

\begin{tabular}{|c|c|c|c|c|c|c|c|c|}
\hline \multicolumn{5}{|c|}{ Test type } & \multicolumn{2}{|c|}{ B resamples } & \multicolumn{2}{|l|}{ p-value } \\
\hline \multicolumn{5}{|c|}{ Bootstrap } & \multicolumn{2}{|l|}{2000} & \multicolumn{2}{|c|}{ p-boot $=0.0005$} \\
\hline \multicolumn{5}{|c|}{ Second-order Rao-Scott adjust } & \multicolumn{2}{|l|}{2000} & \multicolumn{2}{|c|}{$\mathrm{p}$-adjust $=0.0001$} \\
\hline \multicolumn{5}{|c|}{ Bonferroni adjustment } & \multicolumn{2}{|l|}{2000} & \multicolumn{2}{|c|}{ p-adjust $=0.0001$} \\
\hline \multicolumn{9}{|c|}{ Bonferroni Adjusted Results (p.adj < 0.0001) } \\
\hline & Q8a & Q8b & Q8c & Q8d & Q8e & Q8f & Q8g & Q8h \\
\hline Q3a & 0.000 & 0.000 & 0.1166 & 0.0006 & 0.2855 & 0.000 & 0.0163 & 0.000 \\
\hline Q3b & 0.000 & 0.000 & 1.000 & 0.214 & 1.000 & 0.000 & 0.6688 & 0.000 \\
\hline Q3c & 0.000 & 0.000 & 1.000 & 0.1374 & 1.000 & 0.000 & 0.1374 & 0.000 \\
\hline Q3d & 0.000 & 0.0018 & 1.000 & 1.000 & 1.000 & 0.0008 & 1.000 & 0.000 \\
\hline
\end{tabular}

Result: Both the Bootstrap tests, the Bonferroni and Second-order Rao-Scott Adjusted results gave pvalues of $0.0005,0.0001$ and 0.0001 , respectively, which are all significant at $5 \%$ level. This indicates strong evidence against SPMI. The $X S 2, i, j$ and corresponding Bonferroni adjusted p-values indicate no significant associations between poultry activities (and feed suppliers, private consultancy as sources of information), piggery (and feed suppliers, private consultancy, friends-relatives as sources of information), goats (and feed suppliers, radio-television, online sources and friends and relatives as sources of information) and cattle (feed suppliers, radio- television, online sources, friends and relatives as sources of information. Farmers practicing animal husbandry heavily rely on different sources of information. Those doing poultry activities are not very keen on information search, which might mean farmers know poultry farming information, and it is an easy to do a project.

Note: This particular SPMI test is of interest since many association relationships exist between animal husbandry activities and information sources.

4.1.4. MI.test for association between questions source of information for agricultural activities vs chemicals use

Table 6: MI.test for association between questions source of information for agricultural activities vs chemicals use (herbicides and pesticides)

\begin{tabular}{|c|c|c|c|c|c|c|c|c|}
\hline \multicolumn{5}{|c|}{ Test type } & \multicolumn{2}{|c|}{ B resamples } & \multicolumn{2}{|c|}{ p-value } \\
\hline \multicolumn{5}{|c|}{ Bootstrap } & \multicolumn{2}{|c|}{1998} & \multicolumn{2}{|c|}{ p-boot $=0.0005$} \\
\hline \multicolumn{5}{|c|}{ Second-order Rao-Scott adjust } & \multicolumn{2}{|l|}{1998} & \multicolumn{2}{|c|}{ p-adjust $=0.0001$} \\
\hline \multicolumn{5}{|c|}{ Bonferroni adjustment } & \multicolumn{2}{|l|}{1998} & \multicolumn{2}{|c|}{ p-adjust $=0.0001$} \\
\hline \multicolumn{9}{|c|}{ Bonferroni Adjusted Results (p.adj $<0.0001$ ) } \\
\hline & Q8a & Q8b & Q8c & Q8d & Q8e & Q8f & Q8g & Q8h \\
\hline Q10a & 0.000 & 0.000 & 0.0594 & 0.0001 & 1.000 & 0.000 & 0.0007 & 0.000 \\
\hline Q10b & 1.000 & 1.000 & 1.000 & 1.000 & 1.000 & 1.000 & 0.3629 & 1.000 \\
\hline
\end{tabular}

Result: Both the Bootstrap tests, the Bonferroni and Second-order Rao-Scott Adjusted results gave pvalues of $0.0005,0.0001$ and 0.0001 , respectively, which are all significant at $5 \%$ level. This indicates strong evidence against SPMI. The XS2,i,j and corresponding Bonferroni adjusted p-values generally indicate substantial associations between sources of information and use of herbicides (as chemicals) 
except for feed suppliers and online sources. However, there is no association between sources of information and the use of pesticides.

4.2 Section B: Log-linear tests (testing on type of associations and testing on perfect fit tests)

Log-linear models - The generalized log-linear regressions will answer the question:

What type of associations exists in independence relationships?

The analysis will use the genloglin () function in the MRCV package and use observed odds ratios. Model predicted odds ratios and standardized residuals to decide on the presence or lack of fit on both W-main, Y-main effects or WY-main effects models. If lack of fit is observed, an alternative model is specified using the genloglin ()function for accounting for the heterogeneity factors within an MRCV. Log-linear models are used to model associations in regular contingency tables.

The general hypotheses are as follows:

$H_{0}$ : There is W-homogenous (or Y-main effects or WY-main effects) association.

Vs $H_{1}$ : The saturated model provides a better fit.

The log-linear model that allows association between W and Y (MRCV I vs MRCV 2) can be written as $\log \left(\mu_{i j}\right)=\beta_{0}+\beta_{i}^{W}+\beta_{j}^{Y}+\beta_{i j}^{W Y}$ for $\mathrm{i}=1,2, \ldots, \mathrm{I}$ and $\mathrm{J}=1,2, \ldots, \mathrm{J}$

$\beta_{i j}^{W Y}$ is the interaction term which allows the difference of log mean counts between cells in two rows to change across columns and vice versa and $\beta^{W}=\beta^{Y}=\beta^{W Y}=0$

Bilder and Loughin (2007) generalize log-linear models to test for SPMI and describe any associations' patterns when SPMI does not hold. Log-linear Poisson regression models are useful for describing relationships among categorical variables and estimating the strength of associations using odds ratios. In the context of MRCVs, we can adapt these models both to test for SPMI and to describe associations between MRCVs when SPMI does not hold. This flexibility gives models a distinct advantage over the methods in the previous section.

4.2.1. Log-linear regression between field agricultural activities and use of chemicals (herbicides or pesticides) Q2 vs Q10.

The log-linear regression tests involve testing the type of associations found by testing for both the Ymain effects, W-main effects and WY-main effects and then further extending the test for heterogeneity factors where possible. According to Bilder and Loughin (2007) a constant of 0.5 is added in marginal modeling to each sub-table cell analysis model if they are zero and a sensitivity analysis indicates that smaller constants do not affect the inferences made.

Table 7: Goodness-of fit statistics for models fit to field agriculture activities and use of chemicals, $B=1900$ (and 6000 resamples) for the bootstrap procedure

\begin{tabular}{|l|l|l|l|l|l|}
\hline Model & B-sample & $\begin{array}{l}\text { Pearson } \\
\text { statistic }\end{array}$ & LRT-statistic & Bootstrap p-value & $\begin{array}{l}\text { Second-order Rao-Scott adjusted } \\
\text { p-values }\end{array}$ \\
\hline $\begin{array}{l}\text { Y-homogenous } \\
\text { association }\end{array}$ & 1900 & 8.6 & 8.57 & 0.7924 & 0.7005 \\
\hline $\begin{array}{l}\text { W-homogeneous } \\
\text { association }\end{array}$ & 19000 & 2.18 & 2.17 & 0.9245 & 0.7762 \\
\hline $\begin{array}{l}\text { WY-homogenous } \\
\text { association }\end{array}$ & 6000 & 1.43 & 1.49 & 0.9373 & 0.8112 \\
\hline
\end{tabular}

Table 8: The absolute standardized Pearson residuals $(|\mathbf{r}|)$, observed odds ratios, $\widetilde{\theta}$ and modelpredicted odds ratios, $\overline{\boldsymbol{\theta}}$

\begin{tabular}{|l|l|l|l|l|l|l|l|l|l|l|}
\hline & $\begin{array}{l}\text { Beds- } \\
\text { veg }\end{array}$ & $\begin{array}{l}\text { Beds- } \\
\text { herbs }\end{array}$ & $\begin{array}{l}\text { Beds- } \\
\text { fruits }\end{array}$ & $\begin{array}{l}\text { Sweet } \\
\text { potato }\end{array}$ & $\begin{array}{l}\text { Mushr } \\
\text { oom }\end{array}$ & $\begin{array}{l}\text { Nurser } \\
\text { y seeds }\end{array}$ & $\begin{array}{l}\text { Flow } \\
\text { ers }\end{array}$ & $\begin{array}{l}\text { Groun } \\
\text { dnuts }\end{array}$ & Grains \\
\hline
\end{tabular}




\begin{tabular}{|c|c|c|c|c|c|c|c|c|c|c|c|}
\hline & $\begin{array}{l}|\mathrm{r}| \\
\text { Herbicides } \\
\bar{\theta}\end{array}$ & $\tilde{\theta}$ & $\begin{array}{l}0.96 \\
2.34 \\
1.89\end{array}$ & $\begin{array}{l}0.21 \\
1.36 \\
1.32\end{array}$ & $\begin{array}{l}0.30 \\
3.06 \\
3.18\end{array}$ & $\begin{array}{l}0.67 \\
2.41 \\
2.54\end{array}$ & $\begin{array}{l}0.41 \\
5.14 \\
4.98\end{array}$ & $\begin{array}{l}0.56 \\
4.51 \\
4.2\end{array}$ & $\begin{array}{l}0.38 \\
5.14 \\
4.98\end{array}$ & $\begin{array}{l}0.12 \\
4.66 \\
4.7\end{array}$ & $\begin{array}{l}0.86 \\
2.73 \\
3.19\end{array}$ \\
\hline 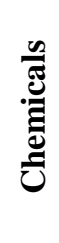 & $\begin{array}{l}|\mathrm{r}| \\
\text { Pesticides } \\
\bar{\theta}\end{array}$ & $\tilde{\theta}$ & $\begin{array}{l}0.96 \\
0.52 \\
1.32\end{array}$ & $\begin{array}{l}0.21 \\
0.8 \\
0.92\end{array}$ & $\begin{array}{l}0.30 \\
2.9 \\
2.22\end{array}$ & $\begin{array}{l}0.67 \\
2.57 \\
1.78\end{array}$ & $\begin{array}{l}0.41 \\
2.7 \\
3.48\end{array}$ & $\begin{array}{c}0.56 \\
1.81 \\
2.94\end{array}$ & $\begin{array}{l}0.38 \\
2.7 \\
3.48\end{array}$ & $\begin{array}{l}0.12 \\
3.57 \\
3.29\end{array}$ & $\begin{array}{l}0.86 \\
3.54 \\
2.23\end{array}$ \\
\hline
\end{tabular}

From the output in table 3.1 and 3.2, $X_{M}^{2}=8.6$ and the corresponding p-value is 0.7294 using the bootstrap approach in the y-main effects model. The p-value using the second-order Rao-Scott approach is 0.7005 . Both p-values indicate that there is no marginal evidence of fit problems with the simpler $Y$ -main-effects model. Comparing the Y-main effects model to the saturated model shows moderate evidence of lack-of-fit. All of the standardized residuals are reasonably small (below 2 in absolute value). These residuals specifically show that the associations across urban farming activities for the chemicals use (herbicides) appear to be as homogeneous as those within the other use of chemicals. This suggests that there is no need for new model which takes this heterogeneity into account, this model (y-main effects) fits better. The W-main effects and WY-main effects results have p-values which are more than 0.05 in value and same conclusions are reached as in the y-main effects model.

Table 3.2 reveals that the standardized Pearson residuals are small. The odds ratio values measure the strength of association in MRCVs: table 3.2 based on 6000 bootstrap resamples reveals that the association between herbicides and agricultural field activities is significantly positive. The association between pesticides and agricultural activities is positive as most predicted odds are above 1 in value with exception of beds-herbs and pesticides. The association between bed-herbs and pesticides is negative possibly because respondents rarely apply pesticides in herbs farming and pests could least attack these. Most farmers use pesticides as opposed to herbicides, hence the positive association in odds ratios although there is a negative relationship between herbs and pesticides. On the other hand, use of herbicides is not prevalent for reasons mainly associated with costs and lack of knowledge, hence the significant association. Obviously, the relationship between agriculture activities and the use of chemicals appear to be as homogeneous as possible. In this case, it can be concluded that there is no need to allow heterogeneity of association.

4.2.2. Log-linear regression between animal agricultural activities and source of information Q3 vs Q8 Table 9: Goodness-of fit statistics for models fit animal agriculture activities and source of information, $B=1900$ (and 5000 resamples) for the bootstrap procedure

\begin{tabular}{|l|l|l|l|l|l|}
\hline Model & B-sample & $\begin{array}{l}\text { Pearson } \\
\text { statistic }\end{array}$ & LRT-statistic & Bootstrap p-value & $\begin{array}{l}\text { Second-order Rao-Scott adjusted } \\
\text { p-values }\end{array}$ \\
\hline $\begin{array}{l}\text { Y-homogenous } \\
\text { association }\end{array}$ & 1900 & 18.45 & 17.33 & 0.1641 & 0.3836 \\
\hline $\begin{array}{l}\text { W-homogeneous } \\
\text { association }\end{array}$ & 1900 & 61.45 & 28.92 & 0.044 & 0.2175 \\
\hline $\begin{array}{l}\text { WY-homogenous } \\
\text { association }\end{array}$ & 5000 & 5.77 & 5.4 & 0.2706 & 0.5591 \\
\hline
\end{tabular}

The marginal modelling approach to test for association between animal husbandry activities and source of information generally provides adequate fits $(0.05<\mathrm{p}$-values $<0.31)$ for bootstrap p-values for both Y-main effects WY-main effects, with exception of W-main effects which shows lack of fit. The Wmain effects models give standardized residuals that are large in value and cannot be adopted even for further heterogeneity tests. However, in the y-main and wy-main effects models, some large standardized Pearson residuals result, with each model having absolute values more than two (2) in size. Using the WY-main effects model results on Pearson residuals, it is observed that there is evidence for lack of fit on the following relationships: $(\mathrm{w} 1, \mathrm{y} 2)$ and $(\mathrm{w} 1, \mathrm{y} 7)$ combinations i.e. (poultry and 
information-magazines) and (poultry and friends-relatives information source) with residuals of size 2.93 and 2.94 respectively. Also, the observed odds ratios are 311.5 and 9.85 for information-magazines and friends-relatives, respectively. Each item's predicted odds ratios are 125.91 and 28.59 for poultry magazines and poultry-friends relatives respectively. It can be concluded that the relationship between poultry and information-magazines and friends-relatives appears not to be homogeneous as it does for the other sources of information in the survey.

There is a need to allow for heterogeneity of association within poultry and magazines, friend-relatives, but not for other information sources.

4.2.2.1. Heterogeneity in $(\mathrm{w} 1, \mathrm{y} 2)$ and $(\mathrm{w} 1, \mathrm{y} 7)$ combinations

modF<-genloglin $($ data $=$ HORT_MTREJ, $\mathrm{I}=4, \mathrm{~J}=8$, model $=$ count $\sim-1+\mathrm{W}: \mathrm{Y}+$ wi $\%$ in $\% \mathrm{~W}: \mathrm{Y}+$ yj\%in\%W:Y + wi:yj + wi:yj\%in\% + wi:yj\%in\%W1:Y2,B=5000)

modG<-genloglin(data $=$ HORT_MTREJ, $\mathrm{I}=4, \mathrm{~J}=8$, model $=$ count $\sim-1+\mathrm{W}: \mathrm{Y}+$ wi $\%$ in $\% \mathrm{~W}: \mathrm{Y}+$ yj\%in\%W:Y + wi:yj + wi:yj\%in\% $Y$ + wi:yj\%in\%W1:Y7,B=5000)

Table 10: Heterogeneity association and goodness-of fit statistics correction tests for models fit animal agriculture activities and source of information, $B=5000$ resamples for the bootstrap procedure

\begin{tabular}{|l|l|l|l|l|l|}
\hline Model & B-sample & $\begin{array}{l}\text { Pearson } \\
\text { statistic }\end{array}$ & LRT-statistic & Bootstrap p-value & $\begin{array}{l}\text { Second-order } \\
\text { adjusted p-values }\end{array}$ \\
\hline $\begin{array}{l}\text { (w1,y2)Poultry- } \\
\text { magazine heterogeneity }\end{array}$ & 5000 & 11.34 & 10.09 & 0.315 & 0.5389 \\
\hline $\begin{array}{l}\text { (y1,y7)Poultry-friends- } \\
\text { relatives heterogeneity }\end{array}$ & 5000 & 18.42 & 17.29 & 0.156 & 0.3764 \\
\hline
\end{tabular}

Heterogeneity tests in Table $4 \mathrm{~b}$ are done with new parameters added to the models to specifically indicate whether or not marginal counts for the poultry activity and information magazines or friendsrelatives information sources. There is a strong positive association between animal husbandry activities and information sources since both observed and model-predicted odds ratios are more than 1 in value. A marginal near-perfect fit is not achieved in the $(\mathrm{w} 1, \mathrm{y} 2)$, poultry-magazine association heterogeneity model because residuals of poultry and state extension workers and farmers associations residuals exceed the absolute value of 2 (have values 2.35 and 2.34 respectively). The re-specified heterogeneity model relationship on the poultry-magazines relationship is probably confounded with the state extension workers and farmers association as source of information. The (w1,y7) heterogeneity association tests resulted in absolute residuals for the (w1, y1) and (w1,y8) combinations (i.e poultry, agriculture extension workers) and (poultry and farmers associations) slightly exceeding set absolute value of 2.0 in values (by 0.03 and 0.12 in values). It can be inferred also that potential lack-of-fit appears to be poultry and more than one source of information source (state extension workers, friendsrelatives and farmers-associations). The resulting model allows researchers to understand better the association structure between animal agricultural activities and information sources. The animal agricultural activities and information sources have a strong positive association between them from the observed and model-predicted odds ratios. For reasons associated with technological changes, magazines are no longer being read. On the other hand, state extension workers' activities and influence are limited in terms of their professional advice to people residing in such areas. Farmers could rely on other sources of information such as farmers associations, friends-relatives, or online sources, as there are positive associations from both observed odds ratios and model-predicted odds ratios.

4.2.3. Log-linear regression between the place of agriculture activities and field agricultural activities Q1 vs Q2.

Table 11: Goodness-of fit statistics for models fit to field agriculture activities and use of chemicals, $B=1900$ (and 6000 resamples) for the bootstrap procedure

\begin{tabular}{|l|l|l|l|l|l|}
\hline Model & B-sample & $\begin{array}{l}\text { Pearson } \\
\text { statistic }\end{array}$ & LRT-statistic & Bootstrap p-value & $\begin{array}{l}\text { Second-order Rao-Scott adjusted } \\
\text { p-values }\end{array}$ \\
\hline $\begin{array}{l}\text { Y-homogenous } \\
\text { association }\end{array}$ & 1900 & 159.58 & 156.99 & 0.0005 & 0.0001 \\
\hline
\end{tabular}




\begin{tabular}{|l|l|l|l|l|l|}
\hline $\begin{array}{l}\text { W-homogeneous } \\
\text { association }\end{array}$ & 1900 & 60.85 & 60.9 & 0.01 & 0.0154 \\
\hline $\begin{array}{l}\text { WY-homogenous } \\
\text { association }\end{array}$ & 3000 & 55.82 & 48.09 & 0.0087 & 0.00462 \\
\hline
\end{tabular}

Both p-values from the Y-main, W-main and WY-main effects models indicate that there is marginal evidence of fit problems. Majority of the standardized residuals are reasonably large (above 2 in absolute value). There are exceptions on the WY-main effects model whereby, most residuals are small (less than 2 in absolute value) with exception of the combinations (w3,y2) and (w4,y3) combinations with large residuals of 2.85 and 3.14 in value. The combinations are namely (plots, beds-herbs) and (plot, beds-fruits). There is a need to take into factor the heterogeneity factors by re-modelling.

\section{Heterogeneity in $(w 4, y 2)$ and $(w 4, y 3)$ combinations}

Table 12: Heterogeneity association and goodness-of fit statistics correction tests for models fit place of agriculture activities and field agriculture activities, $B=3000$ (and 500 resamples) for the bootstrap procedure

\begin{tabular}{|l|l|l|l|l|l|}
\hline Model & B-sample & $\begin{array}{l}\text { Pearson } \\
\text { statistic }\end{array}$ & LRT-statistic & $\begin{array}{l}\text { Bootstrap p- } \\
\text { value }\end{array}$ & $\begin{array}{l}\text { Second-order } \\
\text { adjusted p-values }\end{array}$ \\
\hline $\begin{array}{l}\text { (w4,y2) PLOT-Vegbeds } \\
\text { heterogeneity }\end{array}$ & 5000 & 155.17 & 152.32 & 0.0001 & 0.0002 \\
\hline $\begin{array}{l}\text { (W4,y3) Plot-beds-fruits } \\
\text { heterogeneity }\end{array}$ & 5000 & 133.17 & 130.74 & 0.002 & 0.0001 \\
\hline
\end{tabular}

Heterogeneity tests are done with new parameters added to the models to indicate whether or not marginal counts are for the place of agriculture activities and type agriculture activities. A marginal near-perfect fit is not achieved in both models. The plots-herbs heterogeneity association tests revealed that residuals are large in value hence the lack of fit problems. There is a strong negative association between municipality vacant places and field agricultural activities since most observed and modelpredicted residuals are less than 1 in value in both heterogeneity correction tests.

\section{Conclusion, limitations and study forward}

The aim of the research was in two-fold: firstly, testing on Simultaneous Pairwise Marginal Independence (SPMI) for associations in pairs of Multiple Response Categorical Variables (MRCVs) using the MI.test and secondly, test type of associations using the log-linear modelling of the genloglin () functions using $\mathrm{R}$ software based on the MRCV package. The MI.test revealed that several associations exist between the following pairs of MRCVs: (place of agriculture activities, field agriculture activities), (agriculture field activities, chemicals usage), (animal husbandry, source of information) and (source of information, chemicals usage). The log-linear model applied both the Whomogeneous association, the Y-homogenous association and WY-main effects were applied in the testing for type of association models and lack of fit (through heterogeneity factors tests). The field agriculture activities and chemicals usage MRCVs pair revealed a perfect fit on both W, Y and WYmain effects models with small standardized Pearson residuals and strong positive associations revealed by both observed and model-predicted residuals. The animal husbandry and source of information revealed both lack of fit and partial fit in $\mathrm{Y}$ main effects and WY-main effects models. Further application of heterogeneity correction tests on poultry and magazine or friends-relatives revealed partial marginal fit in models. The field agriculture activities and chemicals usage MRCVs pair revealed lack of fit problems and further heterogeneity tests also failed to achieve a perfect fit in both models respecified. The log-linear tests results show that there is evidence of a strong negative association between municipality vacant places and field agriculture activities. It can be settled here that the saturated model provides better fit than other specified models in such circumstances.

From our hypothesis, we conclude that an association does exist between MRCV as signified by a positive association between information sources and agriculture activities and a negative association between state extension officers. The implication of this is that animal husbandry was never planned for peri-urban and urban areas due to competing needs with urban population. Hence government veterinary extension workers are not readily available to provide services and consulting them attracts 
additional cost, so farmers prefer other sources of information. Another significant association is noted with the use of chemicals and fertilizers, a positive association is evident with field crops but not with flowers, groundnuts, grains. Implying that farmers if crops are not produced for food security or for sale farmers do not see the urge to use chemicals. The log-linear model managed to predict that agriculture activities increase chemical usage. The association and no association observed are of significance in urban agriculture planning, especially in enacting urban agriculture laws, agriculture one stop shop business centers housing farm input supply shops, farm produce shops, and determining fit support that can be rendered to urban farmers.

The research could not carry out log-linear model associations of three or more MRCVs because files exceeded 2GB in memory on both MI.test () function for SPMI tests and genloglin regressions. Secondly, another limitation was on heterogeneity of association within an MRCV sub-item in some instances to reduce residuals to absolute magnitudes of two or less in size, there is need for research on how to hold other item in one MRCV constant within the MRCV package to improve of fit problems involving heterogeneity re-specifications (probably there are confounding relationships in some MRCVs for example on sources of information). The other limitation of the study is that it did not factor in Type I error simulations for model comparisons performance on the correct size of I and J different values under the SPMI hypothesis. A recommendation for future research is that a bigger sample size larger than 115 need to be used and further development of models using single response categorical variables (SRCV) and other types of categorical variables such as ordinal for future researches and inturn application of robust tests such as the Cochran-Mantel-Haenszel (CMH) tests applied.

\section{Author contributions}

Absai Chakaipa conceived the idea from the first paper as he pointed it out to extend our initial research work and overcome its limitations. He rebirthed the idea and did the data analysis as he is our statistician guru. Vitalis Basera, coordinated the flow of the research article guiding its structure from initial paper. Phamela Dube did literature review on MRCVs. All the authors participated in data collection and reaching to the conclusions of the study. The authors declare no conflict of interest

\section{References}

Agresti, A., \& Liu, I. (1999). Modeling a categorical variable allowing arbitrarily many category choices. Biometrics, 55(3), 936-943.

Agresti, A., \& Liu, I. (2001). Strategies for modeling a categorical variable allowing multiple category choices. Sociological Methods \& Research, 29(4), 403 - 434.

Alalaya, M. (2011). Logistic regression vs. log linear models, application of heart diseases through Jordan patient's data. International Journal of Engineering Research \& Technology, 6(7). Retrieved from http://www.ijert.org.

Amao, I. (2020). Urban Horticulture in Sub-Saharan Africa. In Open access peer-reviewed chapter. IntechOpen.

Basera, V. (2021). Introduction to Research Method: Simplified for Tourism Students. Harare: Unpublished.

Basera, V., Chakaipa, A., \& Dube, P. (2020). Impetus of urban horticulture on open spaces: case of Mutare City. Journal of Social, Humanity, and Education, 1(1), 27-37. doi:doi.org/10.35912

Bilder, C. R., \& Loughin, T. M. (2004). Strategies for modeling two categorical variables with multiple category choices. American Statistical Association Proceedings of the Section on Survey Research Methods, 560 - 567.

Bilder, C. R., \& Loughin, T. M. (2007). Modeling association between two or more categorical variables that allow for multiple category choice. Communication in Statistics- Theory and Methods, 36(1-4), 433-, 36: 1-4, 433-455.

Bilder, C., \& Loughin, T. (2001). On the first-order Rao-Scott correction of the Umesh-LoughinScherer statistics. Biometrics, 57(4), 1253-1255.

Bilder, C., \& Loughin, T. (2004). Testing for marginal independence between two categorical variables with multiple responses. Biometrics, 60(1), 241- 248.

Chaminuka, N., \& Dube, E. (2017). Urban agriculture as a food security strategy for urban dwellers: a case study of Mkoba residents in the city of Gweru, Zimbabwe. International Journal of Social Sciences, 3(2), 26-35. 
City of Mutare. (2020). City of Mutare. Retrieved July 29, 2020, from www.nutarecity.co.zw

Coull, B., \& Agresti, A. (2000). Random Effects Modeling of Multiple Binomial Responses Using the Multivariate Binomial Logit-Normal Distribution. Biometrics, 56, 77-80.

Danso, G., Hope, L., \& Drechsel, P. (2014). Financial and economic aspects of urban vegetable farming. In P. Drechsel \& B. Keraita (Eds.), Irrigated urban vegetable production in Ghana: Characteristics, benefits and risk mitigation Colombo: I. International Water Management Institute (IWMI)., 38-50.

Decay, Y. J., \& Thomas, D. R. (2000). A simple test of association for contingency tables with multiple column responses. Biometrics, 56, 893-896.

Edmondson, J. L., Cunningham, H., Tingley, D. O., Dobson, M. C., Grafius, D. R., Leake, J. R., . . . Cameron, D. D. (2020). The hidden potential of urban horticulture. Nature food, 1(3), 155 .

Eigenbrod, C., \& Gruda, N. (2015). Urban vegetable for food security in cities. A review. Agron. Sustain. Dev., 35, 483-498.

FAO. (2007). Profitability and sustainaibility of peri and urban agriculture. FAO.

FAO. (2015). Status of the World's Soil Resources. Rome: FAO.

FAO. (2020). Zimbabwe agriculture country report. Rome: Food and Agriculture Organization of the United Nations.

Gandawa, G. (2020). Urban agriculture: opportunities we refuse to see, white paper. Godfrey Ganadwa.

Gondo, R., Madigele, P. K., Mogomotsi, G. E., Tokwe, T., Jeremiah, C., \& Chirefu, H. (2017). Sustainability of urban agriculture under economic and political instability in Karoi, Zimbabwe. Global Journal of advanced research, 4(2), 52-62.

Gwetsayi, R. T., Dube, L., \& Mashapa, C. (2016). Urban horticulture for food security and livelihood restoration in Mutare City, Eastern Zimbabwe. Greener Journal of Social Sciences, 6(3), 5664.

Hooker, T. (2013). California's green economy trends relationships between firms and their employment outcomes. California Employment Development Department (EDD.

Kawadza, T. S. (2019). Role of urban agriculture. Harare: Herald.

Kennard, N. J., \& Bamford, R. H. (2020, August 27). researchgate.net. Retrieved August 27, 2020, from www.researchgate.net

Koziol, N., \& Bilder, C. (2014). MRCV Methods for analyzing multiple response categorical variables. $R$ package version 0.3-1. Retrieved from http://CRAN.R-project.org/package=MRCV

Lavassani, K., Movahedi, B., \& Kumar, V. (2009). Developments in analysis of multiple response survey data in categorical data analysis: the case of enterprise system implementation in large North American firms. Journal of applied quantitative methods, 4(1), 53.

Lorenzoni, G., Sabato, S. S., Lanera, C., Bottigliengo, D., Minto, C., Ocagli, H., . . Pisanò, F. (2019). Comparison of machine learning techniques for prediction of hospitalization in heart failure patients. Journal of clinical medicine, 8(9), 1298. Retrieved from https://doi.org/10.3390/jcm8091298

Loughin, T. M., \& Scherer, P. N. (1998). Testing association in contingency tables with multiple column responses. Biometrics, 54, 630-637.

Martin-Moreau, M., \& Ménascé, D. (2019). Urban Agriculture: Another Way to Feed Cities. Field Actions Science Reports, 20.

Mkhokheli, S. (2012). Do Urban Community Gardens Matter? : The case of Bulawayo Metropolitan province in Zimbabwe. Mediterranean Journal of Social Sciences, 3(9).

Mouget, L. J. (2000). Urban agriculture: definition, presence, potentials and risks, and policy challenges. International Development Research Centre (IDRC).

Nwosisi, S., \& Nandwani, D. (2018). Urban horticulture: overview of recent developments. In Urban Horticulture, Sustainable Development. Springer International Publishing AG, part of Springer Nature.

Poverty Reduction Trust. (2019). Hazardous Urban farming practices: a stumbling block to sustainable development. Harare: Poverty Reduction Trust.

Rao, J. N., \& Scott, A. J. (1981). The analysis of categorical data from complex sample surveys: Chisquared tests for goodness of fit and independence in two-way tables. Journal of the American Statistical Association, 76, 221 - 230. 
RUAF. (2020). Resource Center on Urban Agriculture and Food Security (RUAF) Foundation. Retrieved August 22, 2020, from www.ruaf.org

Stallings, R., \& Ferris, J. (1988). Public administration research: Work in PAR', 1940-1984. Public Administration Review, 48, 580-587.

Tudor, V., Micua, M. M., \& Condeia, R. (2014). Vision analysis on the type of agriculture agricultural producers deemed necessary to be practiced in the arges county production growth and yield return. Procedia Economics and Finance, 16, 526 - 534.

Umesh, U. N. (1995). Predicting nominal variable relationships with multiple responses. Journal of Forecasting, 14, 585-596.

World Bank. (2020). Zimbabwe overview. Washington, DC: The World Bank.

Zhu, B., S.D., W., P.L., R., D.J., R., \& Parminder, R. (2006). Structural equation and log-linear modeling: a comparison of methods in the analysis of a study on caregivers' health. BMC Medical Research Methodology. doi:doi:10.1186/1471-2288-6-49

Ziwenga, T. F. (2014). The viability of urban agriculture in reducing food insecurity in Gweru, Mkoba 19 suburb. Gweru: Midlands State University. 